\title{
Analysis of Chemical Composition of Portland Cement in Ghana: A Key to Understand the Behavior of Cement
}

\author{
Mark Bediako $^{1}$ and Eric Opoku Amankwah ${ }^{2}$ \\ ${ }^{1}$ CSIR-Building and Road Research Institute, Materials Engineering Division, Kumasi, Ghana \\ ${ }^{2}$ Development Office, University of Education, Winneba, Kumasi Campus, Kumasi, Ghana \\ Correspondence should be addressed to Mark Bediako; b23mark@yahoo.com
}

Received 22 May 2015; Revised 16 September 2015; Accepted 16 November 2015

Academic Editor: Wei Liu

Copyright (c) 2015 M. Bediako and E. O. Amankwah. This is an open access article distributed under the Creative Commons Attribution License, which permits unrestricted use, distribution, and reproduction in any medium, provided the original work is properly cited.

\begin{abstract}
The performance of Portland cement in concrete or mortar formation is very well influenced by chemical compositions among other factors. Many engineers usually have little information on the chemical compositions of cement in making decisions for the choice of commercially available Portland cement in Ghana. This work analyzed five different brands of Portland cement in Ghana, namely, Ghacem ordinary Portland cement (OPC) and Portland limestone cement (PLC), CSIR-BRRI Pozzomix, Dangote OPC, and Diamond PLC. The chemical compositions were analyzed with X-Ray Fluorescence (XRF) spectrometer. Student's $t$-test was used to test the significance of the variation in chemical composition between standard literature values and each of the commercial cement brands. Analysis of variance (ANOVA) was also used to establish the extent of variations between chemical compositions and brand name of the all commercial Portland cement brands. Student's $t$-test results showed that there were no significant differences between standard chemical composition values and that of commercial Portland cement. The ANOVA results also indicated that each brand of commercial Portland cement varies in terms of chemical composition; however, the specific brands of cement had no significant differences. The study recommended that using any brand of cement in Ghana was good for any construction works be it concrete or mortar formation.
\end{abstract}

\section{Introduction}

Portland cement is without any argument among the most important and necessary materials in the world. Without it, the construction industry that utilizes huge tonnages of concrete annually would struggle to survive. Besides this, concrete is rated as the second most highly consumed product after water [1]. It is known that some developed countries depend on the construction industry as one of the main pillars for the growth of their economies. In developing economies, the construction industry provides many jobs for people in both the formal and the informal sectors. Any shortfall that stagnates the construction industry usually leads to serious economic slump.

The Ghanaian construction industry depends hugely on Portland cement for almost every type of construction including bridges, offices, and residential facilities [2]. It is estimated that approximately four million tonnes was utilized in 2014. The prediction is that cement consumption may hit a record high of about five million tonnes by 2020. In Ghana, until 2002, the cement industry was monopolized by Ghana cement manufacturers (Ghacem). After the breakdown of the monopoly, the cement industry has witnessed the influx of many other sources of cement products. Some of these Portland cement products are imported from China, India, and other western European countries. Currently the cement market is diverse and huge and therefore customers have the power to make choices. Available Portland cement products that builders depend on are normally the brands from Ghacem, West Africa cement manufacturers (Wacem), and the Dangote cement. The Ghanaian cement market in recent years has seen the influx of minor entrants like Fortress, and so forth. 
The breakdown of cement monopoly which allowed the entrance of other brands of cement is currently creating a major problem for builders in making the best and preferred choice of cement for their constructional work. Engineers and other related building professionals are always confronted with the tough task of selecting the best cement brand in the Ghanaian cement market. The reason for this is because usually masons who normally use the cement products give out various complains to clients who are the main financiers. Sometimes masons complaints are justified; however, the details of their complaints really lack engineering basis.

Most Ghanaian engineers in construction which is largely made of mostly civil engineers make their preferred choice of Portland cement based on strength classification. However, other information such as chemical composition, mineralogical, and even physical properties could be used to corroborate with strength in making good decisions on the best cement in the market. This could be an important key for the selection of best performing cement. In this work, commonly used available Portland cement in the Ghanaian cement market was analyzed in terms of its oxide composition. The main aim of the study was to determine the extent of variation that exists between the commercially available cement and standard literature requirements. In achieving the main aim of the work, the study was guided by this hypothesis "Is there any major differences between the chemical compositions of Ghanaian commercial Portland cement and standard requirements from literature?"

\section{Literature Review}

Portland cement is the most commonly utilized cement in almost every part of the world. The understanding of the embodiment of Portland cement could lead to a more sustainable concrete and mortar design. It chemically reacts with water to attain setting and hardening properties when used in the construction of buildings, roads, bridges, and other structures. Portland cement was patented by Joseph Aspdin in 1824 and was named after the cliffs on the isle of Portland in England [3].

The production of Portland cement is made by the calcination of a mixture of a calcareous and an argillaceous material at a temperature around $1450^{\circ} \mathrm{C}$ [7]. Calcareous substances are of calcium oxide origin usually found in limestone, chalk, or oyster shells whereas argillaceous substances are of silicate and aluminate origin predominantly found in clays, shale, and slags [4]. The calcination process between well-proportioned argillaceous and calcareous substances leads to the production of clinker. Portland cement is obtained when the produced clinker is mixed together with a predefined ratio of gypsum and milled together in a ball mill.

The chemical composition of Portland cement involves both major and minor oxides [5]. The major oxides include $\mathrm{CaO}, \mathrm{SiO}_{2}, \mathrm{Al}_{2} \mathrm{O}_{3}$, and $\mathrm{Fe}_{2} \mathrm{O}_{3}$ whereas the minor oxides also include $\mathrm{MgO}, \mathrm{SO}_{3}$, and some alkali oxides $\left(\mathrm{K}_{2} \mathrm{O}\right.$ and $\mathrm{Na}_{2} \mathrm{O}$ ) and sometimes the inclusion of other compounds, $\mathrm{P}_{2} \mathrm{O}_{5}, \mathrm{Cl}, \mathrm{TiO}_{2}, \mathrm{MnO}_{3}$, and so forth [5]. Each of the oxides performs unique work during cement hydration; however,
TABLE 1: Summary of chemical data for a selection of Portland cement.

\begin{tabular}{lccc}
\hline Component & Minimum & Average & Maximum \\
\hline $\mathrm{SiO}_{2}$ & 18.40 & 21.02 & 24.50 \\
$\mathrm{Fe}_{2} \mathrm{O}_{3}$ & 0.16 & 2.85 & 5.78 \\
$\mathrm{Al}_{2} \mathrm{O}_{3}$ & 3.10 & 5.04 & 7.56 \\
$\mathrm{CaO}$ & 58.10 & 64.18 & 68.00 \\
$\mathrm{MgO}$ & 0.02 & 1.67 & 7.10 \\
$\mathrm{SO}_{3}$ & 0.00 & 2.58 & 5.35 \\
$\mathrm{Na}_{2} \mathrm{O}$ & 0.00 & 0.24 & 0.78 \\
$\mathrm{~K}_{2} \mathrm{O}$ & 0.04 & 0.70 & 1.66 \\
Equivalent alkalis & 0.03 & 0.68 & 1.24 \\
Free lime & 0.03 & 1.24 & 3.68 \\
\hline
\end{tabular}

each content of the oxide must be in the right quantity during proportioning of raw materials [6]. Lea [7] provided the required oxide composition of Portland cement (see Table 1). A deviation from standard specifications of the oxide composition may lead to unsoundness and sometimes failure of concrete structures. Many experienced authors have shown that cement oxides which fall very close to the average values are more suitable to maintain concrete integrity $[8,9]$.

During cement hydration $\mathrm{CaO}$ in conjunction with $\mathrm{SiO}_{2}$, $\mathrm{Al}_{2} \mathrm{O}_{3}$, and $\mathrm{Fe}_{2} \mathrm{O}_{3}$ leads to hardening of Portland cement due to the formation of calcium aluminosilicates and aluminoferrite hydrate. With Portland cement, an increased presence of $\mathrm{MgO}$ (greater than 2\%) may be detrimental to the soundness of cement, especially at late ages. High percentage of $\mathrm{SO}_{3}$ tends to cause unsoundness of cement. For the Americans in their standard, ASTM C618 limits $\mathrm{SO}_{3}$ to $4 \%$ and $5 \%$ whilst the Indian standard limits $\mathrm{SO}_{3}$ to $2.75 \%$. Alkalis at higher levels and in the presence of moisture gives rise to reactions with certain types of aggregates to produce gel which expands and gives rise to cracking in mortars and concretes.

Sometimes Loss on Ignition (LOI) is classified as a component of chemical composition. LOI indicates the amount of unburnt carbon in the material. However, in some instances it may not necessarily be a measure or indication of carbon content. It may be burning away of residual calcite, bound water molecules, and clay materials [10]. High LOI content may be detrimental to concrete and mortar. It is also known that a high value of LOI results in increased water requirement and dosage of super plasticizer usage in mortar and concrete [11]. Maximum LOI values for both American and Indian standards for common pozzolanic material are $10 \%$ and $12 \%$, respectively.

\section{Materials and Experimental Procedure}

The Portland cement analyzed was five main available commercial cement brands in Ghana which included Ghacem OPC (Class 42.5N) and PLC (Class 32.5R), BRRI Pozzomix, Dangote brand (Class 42.5R), and Diamond brand (Class $42.5 \mathrm{~N}$ ). These brands of cement were obtained in $50 \mathrm{~kg}$ bags from a cement distribution outlet in Kumasi, the second biggest city of Ghana. A representative sample of about $20 \mathrm{~g}$ 
was taken from the bulk $50 \mathrm{~kg}$ bags as received from the factory for the chemical analysis.

The chemical compositions were performed with the XRay Fluorescence (XRF) by the name Spectro X-Lab 2000, at the Ghana geological survey in Accra. The XRF machine uses a polarized energy dispersion. About $4 \mathrm{~g}$ of the cement sample was mixed with about $0.09 \mathrm{~g}$ of wax. The mixture was milled in a milling machine (RETSCH Mixer Miller (MM 301)) for about three minutes to produce a homogeneous mixture, obtaining a particle size of about $60 \mu \mathrm{m}$. The mixture was placed in a dice and placed under the press pellet equipment (SPECAC hydraulic press). The equipment produced a pellet and was then placed in the Spectro X-Lab instrument. The major and other minor oxides were described in graphical histogram presentation. The chemical compositions of each sample were performed three times. The average values of each brand cement were analyzed against the average composition of cement provided by Lea [7] using Student's $t$-test at alpha $(\alpha)$ value of 0.05 . The hypothesis made for the $t$-test was

$$
\begin{aligned}
& \text { Ho: } \mu_{1}=\mu_{2}, \\
& \text { Ha: } \mu_{1} \neq \mu_{2},
\end{aligned}
$$

where $\mu_{1}$ and $\mu_{2}$ are the mean values of average composition by Lea [7] and commercial Portland cement, respectively.

After Student's $t$-test, analysis of variance (ANOVA) was used to determine the extent of variation that existed in commonly used Portland cement in Ghana. The hypothesis that was established was that

$$
\begin{aligned}
& \text { Ho: } \mu_{1}=\mu_{2}=\mu_{3}=\mu_{4}=\mu_{5}, \\
& \text { Ha: } \mu_{1} \neq \mu_{2} \neq \mu_{3} \neq \mu_{4} \neq \mu_{5},
\end{aligned}
$$

where $\mu_{1}, \mu_{2}, \mu_{3}, \mu_{4}$, and $\mu_{5}$ are the mean values of Ghacem OPC, Ghacem PLC, CSIR-BRRI Pozzomix, Dangote OPC, and Diamond PLC. The alpha $(\alpha)$ value used for the ANOVA test was 0.05 .

\section{Results and Discussions}

Figures 1(a)-1(e) present the chemical compositions of the commercial cement available in Ghana. The figure showed the major and the minor oxides present in the Portland cement. A comparison with each cement brand indicated variations in the chemical compositions existing between them. From Figure 1, the predominant oxide compositions were $\mathrm{CaO}$ followed by $\mathrm{SiO}_{2}, \mathrm{Al}_{2} \mathrm{O}_{3}$, and then $\mathrm{Fe}_{2} \mathrm{O}_{3}$ in that order. The minor oxides included $\mathrm{MgO}, \mathrm{Na}_{2} \mathrm{O}, \mathrm{K}_{2} \mathrm{O}$, $\mathrm{MnO}, \mathrm{TiO}_{2}, \mathrm{P}_{2} \mathrm{O}_{5}$, and $\mathrm{SO}_{3}$. The compositions of the various oxides in the commercial Portland cement shown in Figure 1 fall within the requirements of cement oxide compositions provided by Lea [7] and Neville [12] who also obtained similar compositions but at different percentages in their studies.

4.1. Student $t$-Test. Table 2 presents the predictive $(P)$ values and remarks of Student's $t$-test performed between the average chemical composition values provided by Lea [7]
TABLE 2: Predictive values and remarks of Student's $t$-test between average and various cement brands.

\begin{tabular}{lcc}
\hline Brand & $P$ value & Remark \\
\hline Ghacem OPC & 0.96 & Failed \\
Ghacem PLC & 0.93 & Failed \\
BRRI Pozzomix & 0.91 & Failed \\
Dangote OPC & 0.96 & Failed \\
Diamond OPC & 0.98 & Failed \\
\hline
\end{tabular}

and each of the commercial Portland cement brands. All the $P$ values indicated that the test failed to reject the hypothesis that there is any significant effect between the average literature composition values and the commercial Portland cement. This indicated that commercial Portland cement in Ghana is well within and without any major deviation from accepted generalized standard specifications.

4.2. Analysis of Variance. Table 3 presents the results of the ANOVA test performed among commercial Portland cement brands. The results gave a predictive value of approximately $3.927 E-19$ for the rows which represented the chemical compositions whereas that for the columns was approximately 0.85 representing the various brands of the commercial Portland cement. The predictive values indicated that there exists a significant difference with respect to the chemical compositions among cement brands. The variation in chemical composition may be attributed to the differences in the proportioning of raw materials and the nature of production used to produce Portland cement. However, with respect to Portland cement brands, any of them could be used for construction since there were no significant differences.

\section{Conclusions}

The chemical compositions of commonly used Portland cement in Ghana were analyzed with both spectroscopic analysis and statistical tools. Generally, Student's $t$-test results confirmed that, with regards to chemical composition, all commonly used cement in the country has no deviation from standard requirements prescribed from the literature. This therefore shows that any of the commercial cement brands is very suitable for construction or concrete works. However, the Anova output indicated that each brand of commercial Portland cement has individual variations with respect to chemical composition. This is due to the differences that exist with individual factory proportioning of raw materials for Portland cement production.

\section{Conflict of Interests}

The authors declare that there is no conflict of interests regarding the publication of this paper. 


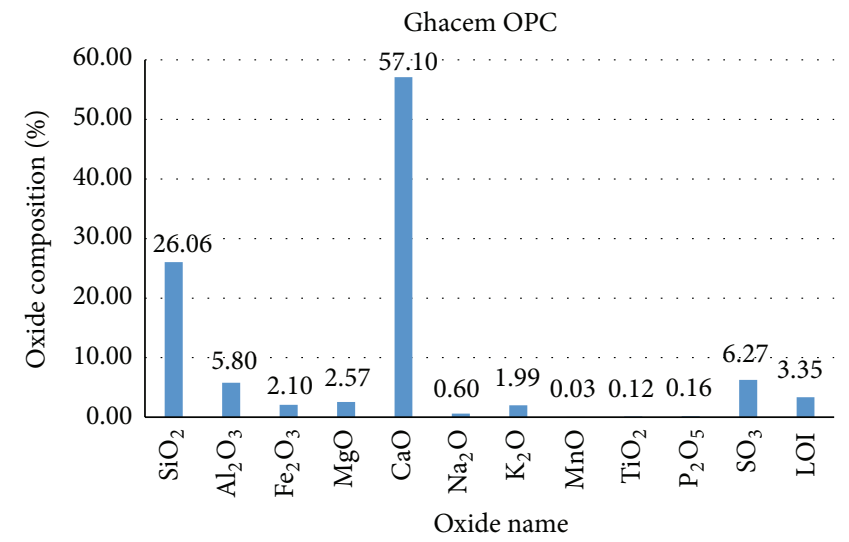

(a)

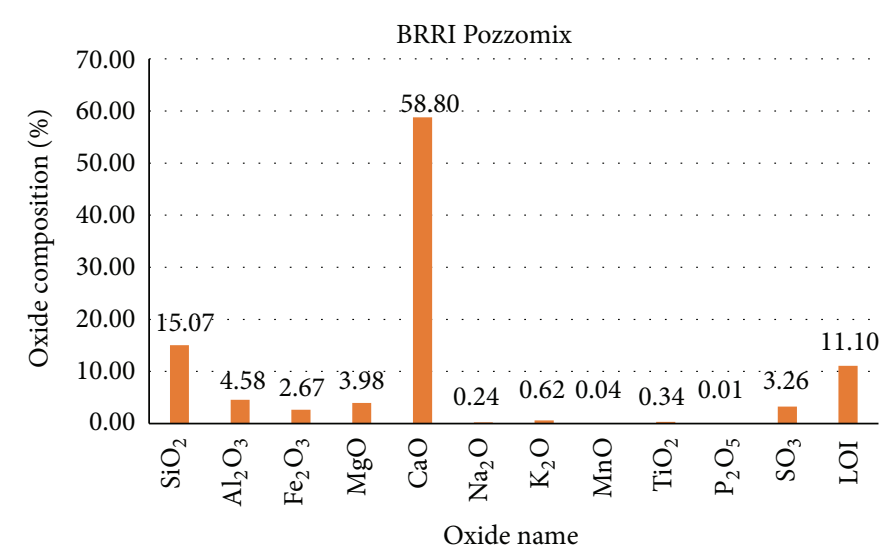

(c)

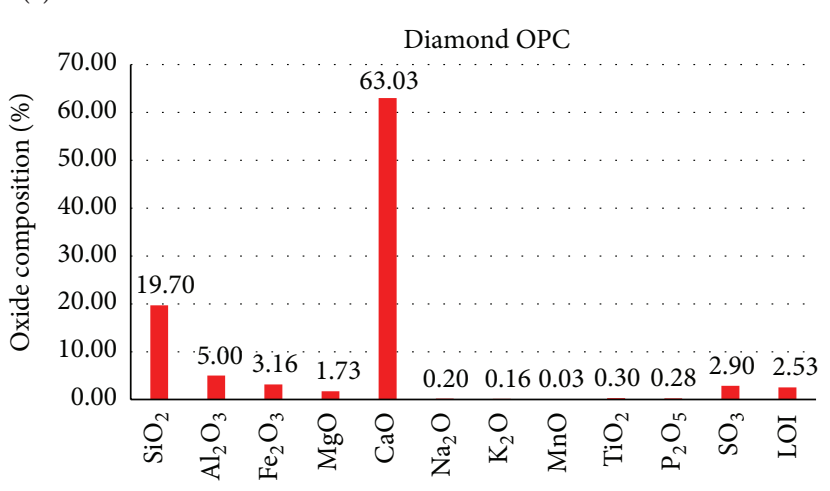

Oxide name

(e)

FIgURE 1: Oxides composition of commercial Portland cement in Ghana.
Ghacem PLC

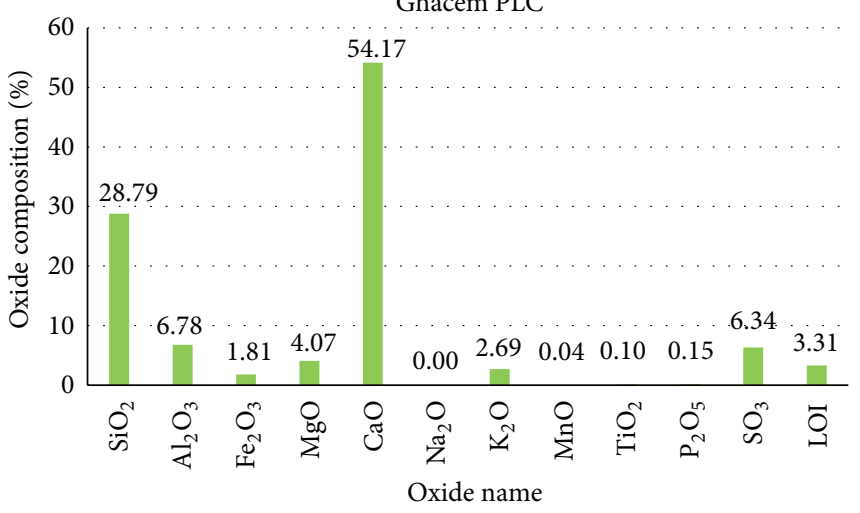

(b)

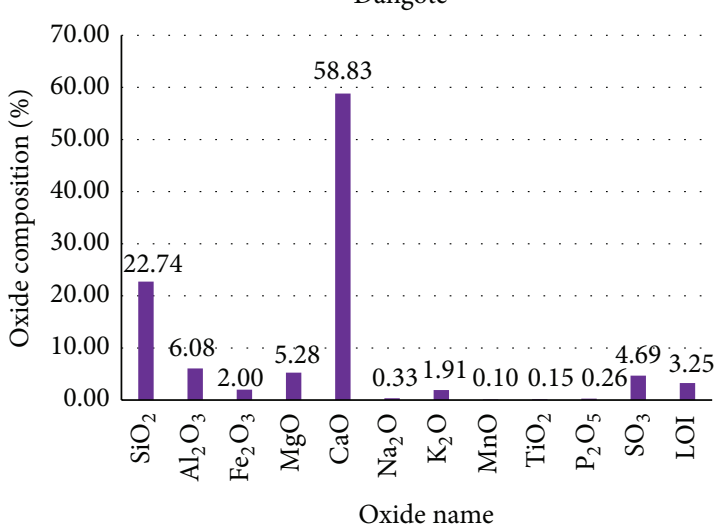

(d)

TABLE 3: ANOVA results of commercial Portland cement.

\begin{tabular}{lccccc}
\hline Source of variation & SS & df. & MS & $F$ & $P$ value \\
\hline Rows & 11320.3788 & 8 & 1415.05 & 167.0854 & $3.927 E-19$ \\
Columns & 6.684288889 & 3 & 2.2281 & 0.263088 & 0.8512781 \\
Error & 203.2561111 & 24 & 8.469 & & 3.00878657 \\
Total & 11530.3192 & 35 & & & \\
\hline
\end{tabular}

SS: sum of squares; df.: degree of freedom; MS: mean square; $F: F$ stat; $F_{\text {crit. }}: F$ critical. 


\section{References}

[1] C. M. Hanson, "Concrete: the advanced industrial material of the 21st century," Metallurgical \& Materials Transactions A, vol. 26, pp. 1321-1341, 1995.

[2] M. Bediako, S. K. Y. Gawu, and A. A. Adjaottor, "Suitability of some Ghanaian mineral admixtures for masonry mortar formulation," Construction and Building Materials, vol. 29, pp. 667-671, 2012.

[3] S. H. Kosmatka, B. Kerkhoff, and W. C. Panarese, Design and Control of Concrete Mixtures, Portland Cement Association, Skokie, Ill, USA, 14th edition, 2002.

[4] M. S. Mamlouk and J. P. Zaniewski, Materials for Civil and Construction Engineers, Prentice Hall, Upper Saddle River, NJ, USA, 2006.

[5] T. Punmatharith, M. Rachakornkij, A. Imyim, and M. Wecharatana, "Co-processing of grinding sludge as alternative raw material in portland cement clinker production," Journal of Applied Sciences, vol. 10, no. 15, pp. 1525-1535, 2010.

[6] D. N. Huntzinger and T. D. Eatmon, "A life-cycle assessment of Portland cement manufacturing: comparing the traditional process with alternative technologies," Journal of Cleaner Production, vol. 17, no. 7, pp. 668-675, 2009.

[7] F. M. Lea, The Chemistry of Cement and Concrete, Arnold Publishers, London, UK, 3rd edition, 1970.

[8] J. F. Young, S. Mindess, R. J. Gray, and A. Bentur, The Science and Technology of Civil Engineering Materials, Prentice-Hall, Upper Saddle River, NJ, USA, 1998.

[9] H. F. W. Taylor, Cement Chemistry, Thomas Telford, London, UK, 2nd edition, 1997.

[10] S. H. Kosmatka and M. L. Wilson, Design and Control of Concrete Mixtures, Portland Cement Association, Stokie, Ill, USA, 2011.

[11] V. Sata, C. Jaturapitakkul, and K. Kiattikomol, "Influence of pozzolan from various by-product materials on mechanical properties of high-strength concrete," Construction and Building Materials, vol. 21, no. 7, pp. 1589-1598, 2007.

[12] A. Neville, Neville on Concrete, ACI, Farmington Hills, Mich, USA, 2003. 

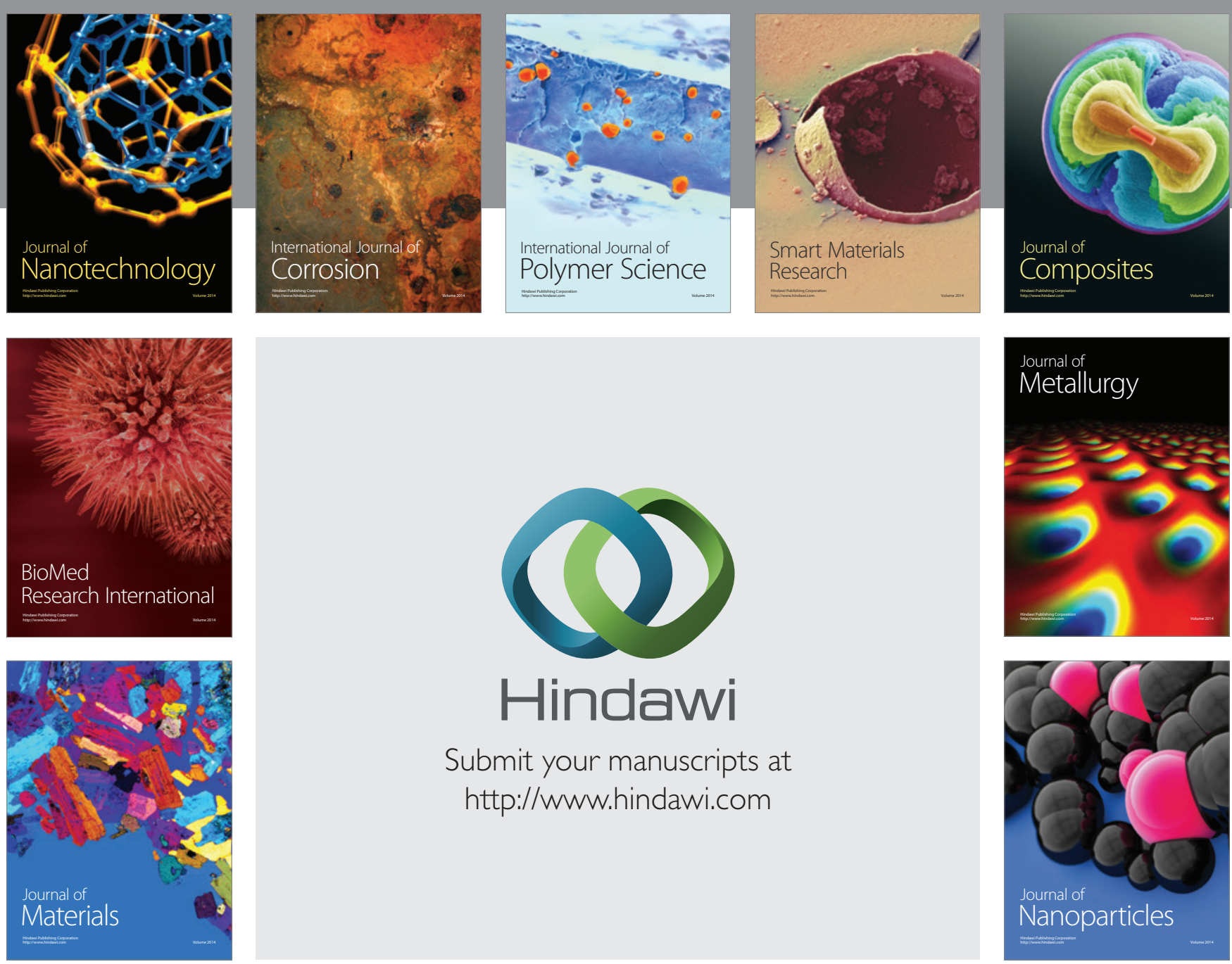

Submit your manuscripts at http://www.hindawi.com
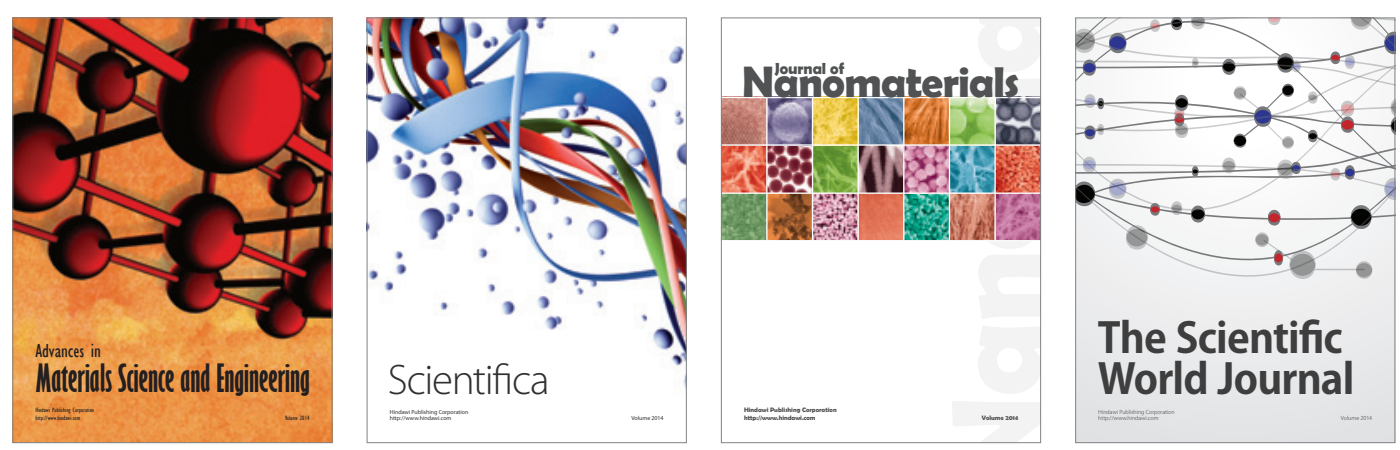

\section{The Scientific World Journal}
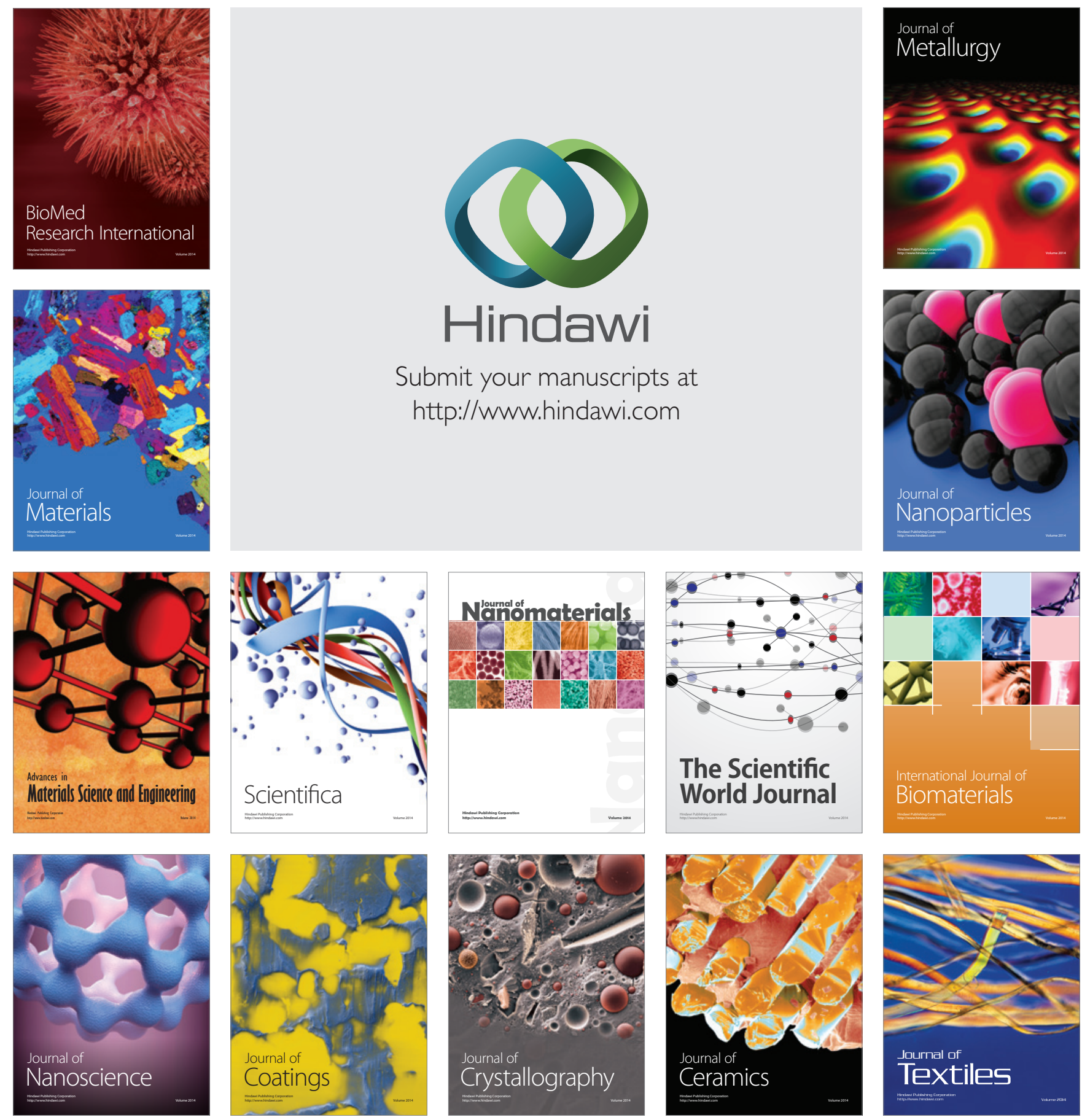